\title{
CONHECIMENTO DIDÁTICO E FORMAÇÃO DE PROFESSORES DE HISTÓRIA: CONTRIBUIÇÕES PARA A TEORIA E A PRÁTICA
}

\author{
PEDAGOGICAL CONTENT KNOWLEDGE AND HISTORY TEACHERS' \\ EDUCATION: CONTRIBUTIONS FOR THEORY AND PRACTICE
}

\author{
Caroline Pacievitch*
}

\begin{abstract}
Este artigo discute a relação entre teoria e prática da formação de professores, defendendo a premissa de que professores constroem conhecimentos de caráter didático. Discutem-se possibilidades teóricas levantadas pelas teorias do Conhecimento Didático do Conteúdo de Lee Shulman e da Didática da História segundo Luis Fernando Cerri, cotejadas à análise de um projeto que envolve docentes universitários, professores da escola básica e estudantes da licenciatura em História. Ampliar conhecimentos sobre o tema auxilia a pensar sobre o papel do professor universitário a partir de perspectivas mais coletivas, reconstruindo a tensão entre teoria e prática.
\end{abstract}

Palavras-chave: Formação de professores de história, conhecimento didático do conteúdo, didática da história.

This paper discusses the relationship between theory and practice in teacher education, defending the premise that teachers build pedagogical knowledge. Theoretical possibilities raised by theories of Pedagogical Content Knowledge (Lee Shulman) and History Didactics (Luis Fernando Cerri) are compared and discussed on the analysis of a project involving university teachers, basic school teachers and university students. To expand knowledge about the topic helps to think about the role of university professor from more collective perspective, rebuilding the tension between theory and practice.

Key words: History teachers education, pedagogical content knowledge, history didactics.

\section{Introdução}

Este artigo se dedica a discutir a relação entre teoria e prática da formação de professores, defendendo a premissa de que professores constroem conhecimentos de caráter didático. Existe uma produção acadêmica considerável que procura explicar os processos de construção de conhecimento de professores e acredita-se que ampliar análises sobre o tema auxilia a pensar sobre o papel do professor universitário responsável por formar docentes para a escola básica. Isso é necessário por ser recorrente, na literatura acadêmica sobre ensino de história, a confiança no trabalho da formação docente para que se concretizem as mudanças almejadas no ensino de história.

Quando se trata de formação de professores de história, pode-se fazer referência a políticas públicas, currículo, estrutura universitária, produção acadêmica, mas também se podem investigar os indivíduos que ensinam a ensinar, isto é, os professores universitários, principalmente aqueles vinculados às disciplinas de prática de ensino e/ou de estágio supervisionado.

A pesquisa cujos resultados parciais subsidiam este artigo tem como ponto de partida o seguinte objetivo: compreender se e como um grupo de quatro professores de história, atuantes na escola básica (professores supervisores), constrói conhecimentos didáticos de forma coletiva, a fim de lançar algumas luzes sobre as possibilidades de ensinar a ensinar história de forma coerente às compreensões alcançadas. Portanto, neste artigo, discutem-se compreensões presentes em parte da literatura acadêmica sobre "conhecimento didático", dialogando com autores como Ana Maria Ferreira da Costa Monteiro, Carlos Marcelo García e Lee Shulman. Tais pensamentos são cotejados a propostas provenientes da Didática da História, conforme Klaus Bergman e Luis Fernando Cerri, entre outros. Por fim, confrontam-se estas reflexões com resultados das análises da pesquisa de

\footnotetext{
* Universidade Federal do Rio Grande do Sul. Porto Alegre, Brasil. Correo electrónico: pacievitch@gmail.com
} 
campo, para construir considerações propositivas para uma formação de professores consequente com as utopias alentadas sobre a escola e o ensino de história.

\section{Relação entre teoria e prática na formação de professores de História}

Quando o tema é formação de professores, um dos problemas mais frequentes é o da relação entre teoria e prática. Depoimentos de professores em formação inicial atestam que esta é uma de suas maiores dificuldades, bem como o alvo mais frequente de críticas sobre o curso de licenciatura, em que há forte separação entre as disciplinas pedagógicas e as historiográficas, sendo que a Didática da História (DH) brilha pela ausência. Em alguns casos, a separação é maior porque as disciplinas ligadas à prática de ensino são ministradas física e burocraticamente separadas do departamento de História. A relação entre teoria e prática é um problema tão frequente que é difícil encontrar artigos sobre formação de professores de história que não se refiram a ele (Pacievitch 2014).

Além disso, os licenciandos também se ressentem da desvalorização da opção pela docência, considerada, por vezes, falta de capacidade para a pesquisa, como se nota no seguinte relato, de uma estudante de licenciatura em História.

Lembro que falar que queria ser professora no início do curso era atestado de mediocridade. Alguns professores adoravam dizer isso. [...] Acho que o grande pecado do nosso curso é esse mundo paralelo entre bacharel e licenciatura [ênfases no original]. Querem que sejamos professores que dialoguem mais com seus alunos, mas isso não está presente no ambiente que estudamos (Costa e Ferreira 2015: 26).

Por vezes, o que se desvaloriza não é o ato de ensinar, mas a possibilidade de refletir e teorizar sobre ele, culminando na crença de que os professores dedicados à prática de ensino ou às ciências da educação não sabem fazer pesquisa, ou, se o fazem, é de maneira frágil e incoerente, como expressaram as professoras Regina e Agnês, entrevistadas quando possuíam quatro e dez anos de vivência docente, respectivamente. [hesitação] É estranho falar isso, mas ... acho que existe um certo... não sei que palavra posso usar pra dizer isso... acho que os historiadores e os pedagogos, não sei como posso dizer ... não é uma rixa, mas existe certo distanciamento [...] somado a isso, que já existe certo distanciamento, a gente, eu não sei, eu acho que a gente não levava muito a sério as matérias daqui [da Faculdade de Educação, sendo aluna da História], isso é horrível falar, mas... [risos] [...] Aí criou-se uma antipatia. Quando a gente vinha fazer matéria aqui, a gente já vinha querendo achar pelo em ovo, sabe? Então, eu acho que eu não aproveitei como eu deveria as matérias que eram propostas (Testemunho da professora Regina. Pacievitch 2014: 159).

Eu estudava para o mestrado, estudava porque eu queria aprender, mas eu estava naquela incógnita, o que eu fazia na sala de aula, eu não usava nada daquilo que eu estudava, diretamente. Parece que deu aquela quebra, como se eu nem tivesse feito mestrado, eu estava meio sapo fora d'água na sala e buscando alguma outra coisa (Testemunho da professora Agnês. Pacievitch 2014: 162).

Às vezes, essa opinião muda ao entrar em contato com professores nas áreas de educação ou ensino que, de alguma forma, causaram impacto nas perspectivas das futuras docentes.

Eu lembro que tinha uma professora daqui [Faculdade de Educação] que eu gostava muito. Agora, qual o nome dela? [...] Já não lembro o nome dela. Mas era uma professora que eu achava exemplar. [...] Só que eu não sei até que ponto a universidade tem que dar... qual é a maneira ideal de preparar um professor? (Testemunho da professora Regina. Pacievitch 2014: 159) Eu copio meus professores da Universidade, que tinham um jeito de dar aula [...]. Vou pegando um pouquinho disso e sou muito grata às minhas parceiras de trabalho que são mais antigas do que eu e eu vou me espelhando muito nelas, nas coisas que elas fazem (Testemunho da professora Mercedes. Pacievitch 2014: 166). 
Tal como o de Mercedes, são recorrentes os relatos que afirmam que se aprende a ser professor não na universidade, mas na prática, com os colegas mais experientes e com os próprios alunos.

[...] Então, esse período [primeiros anos de profissão] foi muito importante porque eu aprendi metodologia de sala de aula. Não sei se essa é a melhor palavra, mas: "como lidar com os alunos". Eu acho que isso é uma coisa que a Faculdade de Educação não prepara. Traz uma série de debates, aprende Piaget, aprende um monte de coisa, mas a prática mesmo de ensino, você não debate na sala, aqui. Você não debate. Mesmo eu tendo assistido aulas na parte de Estágio, você vai na escola, assiste aula e tudo, não existia um debate (Testemunho da professora Regina. Pacievitch 2014: 159). [...] Mas o que eu faço hoje, que humildemente considero um pouco melhor do que o que eu fazia quando eu comecei, é fruto de parceria, de entrosamento do grupo (Testemunho da professora Mercedes. Pacievitch 2014: 166).

Paradoxalmente, na visão destes professores, o curso de formação de professores não os formou para ensinar. Assim, o trabalho de ensinar, na escola básica, é mais frequentemente identificado como oscilando entre a militância e o sacerdócio (Pacievitch e Cerri 2010) do que como tarefa intelectual transformadora, como propõe Henry Giroux (1997) na esteira de Antonio Gramsci e de Paulo Freire.

Se acreditamos que o papel do ensino não pode ser reduzido ao simples treinamento de habilidades práticas, mas que, em vez disso, envolve a educação de uma classe de intelectuais vital para o desenvolvimento de uma sociedade livre, então a categoria de intelectual torna-se uma maneira de unir a finalidade da educação de professores, escolarização pública e treinamento profissional aos próprios princípios necessários para o desenvolvimento de uma ordem e sociedade democráticas (Giroux 1997: 162).

Assentam-se, portanto, duas premissas importantes deste trabalho, a partir da ilustração destes testemunhos: 1) são os próprios professores de história que constatam esta lacuna -e a impossibilidade de resolvê-la- na sua formação, que acaba por naturalizar a separação entre teoria e prática; 2) ao mesmo tempo, defende-se que a profissão docente é trabalho intelectual que transforma (ou seja, onde pensar e agir são indissociáveis) e o faz a partir de uma crítica profunda ao presente, com a formulação de projetos de futuro concretos (Pacievitch 2014). Uma profissão difícil de aprender, amparada em princípios de esperança em futuros melhores e, obviamente, em disputas ideológicas.

A produção acadêmica, apesar de constatar que a relação entre teoria e prática é um dos principais problemas, não conseguiu influenciar suficientemente as práticas da formação inicial e contínua a fim de conduzir a inovações concretas que auxiliem os futuros professores a construir novos saberes sobre seu trabalho. Mas há avanços. As "Diretrizes Curriculares Nacionais para a formação inicial em nível superior (cursos de licenciatura, cursos de formação pedagógica para graduados e cursos de segunda licenciatura) e para a formação continuada", de $1^{\circ}$ de julho de 2015 , superaram -ao menos nos enunciado - um dos principais problemas de suas antecessoras (Guimarães 2001) e uniram alguns dos elementos sugeridos na literatura como essenciais para a construção de conhecimentos necessários à atuação profissional, tais como:

II - a formação dos profissionais do magistério (formadores e estudantes) como compromisso com projeto social, político e ético que contribua para a consolidação de uma nação soberana, democrática, justa, inclusiva e que promova a emancipação dos indivíduos e grupos sociais [ênfases do autor], atenta ao reconhecimento e à valorização da diversidade e, portanto, contrária a toda forma de discriminação; [...]

V - a articulação entre a teoria e a prática [ênfase do autor] no processo de formação docente, fundada no domínio dos conhecimentos científicos e didáticos, contemplando a indissociabilidade entre ensino, pesquisa e extensão;

VI - o reconhecimento das instituições de educação básica como espaços necessários à formação dos profissionais do magistério [ênfase do autor];

[...] 
X - a compreensão da formação continuada como componente essencial da profissionalização inspirado nos diferentes saberes e na experiência docente [ênfase do autor], integrando-a ao cotidiano da instituição educativa, bem como ao projeto pedagógico da instituição de educação básica;

XI - a compreensão dos profissionais do magistério como agentes formativos de cultura [ênfase do autor] e da necessidade de seu acesso permanente às informações, vivência e atualização culturais (Conselho Nacional de Educação 2015: 4-5).

Estas Diretrizes caminham para uma visão de professor que é muito mais que transmissor de conteúdos. São valorizados os conhecimentos acadêmicos, mas submetidos aos interesses dos estudantes e a projetos de futuro emancipadores. Não há dúvidas de que a articulação entre teoria e prática se torna mais complexa pela concepção de professor como agente cultural e na valorização da escola como espaço formador. Fica evidente a necessidade de compreender que tipos de conhecimentos precisa ter o professor de história, conforme estas Diretrizes. Poderiam ser chamados de conhecimentos histórico-didáticos?

\section{Algumas perspectivas sobre conhecimento didático}

Ao buscar artigos acadêmicos utilizando a palavra-chave "conhecimento didático" no instrumento "Google Scholar" (apenas em português), os resultados se concentram majoritariamente em áreas de ciências exatas e da natureza. Os pesquisadores destas áreas escolhem um conteúdo a ensinar (por exemplo, equações de segundo grau) e avaliam os conhecimentos didáticos de professores sobre o tema. Não foi possível encontrar artigos, em português, que vinculassem ensino de história à expressão "conhecimento didático".

Em português, retirando resultados que tratassem de pesquisas sobre um conteúdo específico (ciências da natureza e matemática), encontram-se artigos de autores brasileiros que utilizam o termo para tratar do conjunto de conhecimentos acadêmicos sobre didática, como em André e Cruz (2012) e em Valdés Puentes e Longarezzi (2015). Em Libâneo (2012) a expressão é atribuída ao pesquisador Lee
Shulman, dos Estados Unidos, considerando-o um dos principais autores a tratar detidamente dos conhecimentos que os professores desenvolvem para ensinar.

Libâneo (2012) constrói um diagnóstico sobre o lugar da didática na universidade brasileira, constatando que ela oferece pouca atenção ao que acontece dentro da sala de aula e, quando o faz, o foco é o ensino e não a interlocução com a aprendizagem, confirmando os testemunhos de professores apresentados acima. Com Shulman e Davidov, Libâneo defende o vínculo indissociável entre a epistemologia da ciência de referência e a didática: “(...) A didática articula, simultaneamente, a lógica dos saberes a ensinar (dimensão epistemológica) e a lógica dos modos de aprender (dimensão psico-pedagógica)" (Libâneo 2012: 47), tema melhor debatido ao final deste artigo.

Especificamente em relação ao ensino de história, devem-se mencionar trabalhos de Ana Maria Monteiro (2003 e 2001), que se preocupa com a construção de saberes históricos escolares e dos saberes docentes para ensinar história. Ela discute, avalia e compara possibilidades apresentadas por Yves Chevallard, Alice Lopes, Maurice Tardif, Donald Schön e Philippe Perrenoud, entre outros. A partir da concepção de transposição didática formulada por Chevallard, Monteiro (2003) prefere a expressão mediação didática, que é quando ocorre uma transformação dialética no contato entre diversos tipos de saberes, na constituição do que é o saber ensinado/aprendido na escola.

Assim, ao considerar que o saber histórico veiculado na escola é qualitativamente distinto do saber histórico acadêmico, constrói-se o problema sobre os saberes docentes: o que precisa saber o professor de história para que as futuras gerações aprendam história? Certamente, não basta saber apenas o conhecimento histórico acadêmico. Para tentar responder a este problema, Monteiro recorre ao que Shulman chamou de "missing paradigm": a forma como os professores transformam em ensino aquilo que eles sabem. E, para pensar numa epistemologia da prática, a autora revisa textos de Maurice Tardif e de Donald Schön, pois cada um, à sua maneira, explica que os saberes docentes são construídos na prática, são individuais, exclusivos e não sistemáticos. Entretanto, ela prefere conjugar com a abordagem de Phillipe Perrenoud, pois ele amplia o foco para as competências e não são só para os saberes. 
Temos por hipótese que as adequações que geram o conhecimento escolar, seu contexto de produção e recepção, estão diretamente relacionadas com as necessidades e constrangimentos da prática profissional, o que permite articular essas duas categorias de análise para ampliar o instrumental teórico e poder dar conta do desafio proposto (Monteiro 2001: 138).

A proposta final de Monteiro é de aproximar as abordagens de Shulman e de Perrenoud, já que o primeiro destaca a centralidade do conhecimento específico na constituição dos saberes docentes, enquanto o segundo lembra que a profissão depende de competências para ensinar e não apenas dos saberes.

Essa abordagem conduz à necessidade de melhor investigar o pensamento de Shulman, cuja obra foi discutida e incorporada, em parte, pelo pesquisador espanhol Carlos Marcelo García. Em um livro que sintetiza algumas de suas produções dos anos de 1990, em parceria com a autora uruguaia Denise Vaillant (Marcelo e Vaillant 2001), é exposta uma concepção de educação voltada para atender às necessidades econômicas de um mundo pós-moderno. Relatórios da OCDE embasam a argumentação. Concorda-se com Marcelo de que os jovens precisam ser preparados, na escola, para viver no mundo que lhes foi deixado pelas gerações anteriores. Entretanto, considera-se insuficiente a adaptação ao mercado de trabalho, sendo necessário, do ponto de vista da presente pesquisa, pensar na educação como emancipação e construção de outros futuros possíveis, em busca de justiça social.

Assim, mesmo partindo de diagnósticos diferentes e com projeções de futuro distintas às do presente trabalho, são relevantes as contribuições de Marcelo sobre o papel do formador no processo de ensinar a ensinar. Para Marcelo e Vaillant (2001), o formador precisa ser visto como mediador dos processos de formação. A baixa qualidade dos cursos de formação de professores, em muitos casos, se deve à formação inadequada dos próprios formadores, que, vistos como um "profissional da aprendizagem" (Marcelo e Vaillant 2001: 31), deveriam se conectar às necessidades da formação. É neste ponto que os autores recorrem a Lee Shulman.

Shulman (1992)

${ }^{1}$ manifestaba la necesidad de que los profesores construyeran puentes entre el significado del contenido curricular y la construcción realizada por los alumnos de ese significado. Este prestigioso investigador, afirma que "los profesores llevan a cabo esta hazaña de honestidad intelectual mediante una comprensión profunda, flexible y abierta del contenido; comprendiendo las dificultades más probables que tendrán los alumnos con estas ideas [...]; comprendiendo las variaciones de los métodos y modelos de enseñanza para ayudar a los alumnos en su construcción del conocimiento; $y$ estando abierto a revisar sus objetivos, planes y procedimientos en la medida en que se desarrolla la interacción con los estudiantes. Este tipo de comprensión no es exclusivamente técnica, ni solamente reflexiva. No es solo el conocimiento del contenido, ni el dominio genérico de métodos de enseñanza. Es una mezcla de todo lo anterior, y es principalmente pedagógico" (Marcelo e Vaillant 2001: 42).

Em outra obra, Marcelo destaca o principal aspecto do pensamento de Shulman, a centralidade do Conocimiento Didáctico del Contenido (CDC) para que os professores ensinem com foco nas aprendizagens dos estudantes.

El Conocimiento Didáctico del Contenido aparece como un elemento central de los saberes del formador. Representa la combinación adecuada entre el conocimiento de la materia a enseñar y el conocimiento pedagógico y didáctico referido a cómo enseñarla. [...] El Conocimiento Didáctico del Contenido, como línea de investigación, representa la confluencia de esfuerzos de investigadores didácticos con investigadores de materias específicas preocupados por la formación del profesorado. El Conocimiento Didáctico del Contenido nos dirige a un debate en relación con la forma de organización y de representación del conocimiento, a través de analogías y metáforas. Plantea la necesidad de que los profesores en formación adquieran un conocimiento experto del contenido a enseñar, para que puedan desarrollar una enseñanza que propicie la comprensión de los alumnos (Marcelo 2001: 572). 
Apoiado em McEwan e Bull, Marcelo (1993) alerta que não deveria haver distinção entre conhecimento do conteúdo e conhecimento pedagógico do conteúdo, pois todo conhecimento já envolve uma dimensão pedagógica. É um dilema a ser enfrentado, pois não deveriam ser vistos como distintos, mas na prática são. Como sair desta visão sem depreciar o conhecimento didático docente ao tentar compará-lo com o conhecimento acadêmico do conteúdo? Talvez seja relevante aproximar mais a ideia de conhecimento didático do que propõe a didática da história especificamente, o que será feito no próximo tópico deste artigo.

Aproximando-se de textos do próprio Shulman, percebe-se que o conceito de Pedagogical Content Knowledge (PCK) acompanha a interpretação oferecida por Marcelo. Em Grossman, Wilson e Shulman (2005), há quatro dimensões que influenciam a formação docente: o conhecimento do conteúdo (informação objetiva, princípios, conceitos da ciência de referência), o conhecimento substantivo (paradigmas de pesquisa do campo), o conhecimento sintático (metodologia de construção de conhecimento) e as crenças sobre a matéria (as quais os professores devem reconhecer e analisar).

Assim, no caso dos professores de história, o PCK passaria por saber conteúdos factuais, desde que avaliados a partir dos paradigmas de produção de conhecimento oferecidos pela teoria da história e orientados pelo conhecimento sobre a forma como cada processo foi construído e interpretado, refletindo, ainda, sobre os usos desse conhecimento e seus pressupostos ideológicos. Apesar de separados na argumentação de Shulman, estas quatro dimensões são inseparáveis na construção de conhecimento docente.

Nas pesquisas revisadas por estes autores e em outros artigos de Shulman, nota-se a relevância do PCK para professores que ensinam bem, seja porque aprofundam as explicações conceituais ou porque ensinam a pensar historicamente (ou matematicamente, geograficamente...) para além de repassar conteúdos (Grossman, Wilson e Shulman 2005: 10).

Entretanto, considera-se que o que se está chamando de conhecimento didático, nesta pesquisa, não se restringe ao PCK e, sim, ao que Shulman reiteradamente denomina "pensar como um professor" ou raciocínio pedagógico (Shulman 2014), ou, ainda, construir pensamento didático.

\section{(...) Del mismo modo, Feiman-Nemser y Buchmann (1985a) discuten el concepto de "pensamiento didáctico" como "fundado en el conocimiento de sí mismo, de los niños y de la materia" (pp. 1-2). Así, pensar como un profesor requiere la consideración del contenido a la luz de las cuestiones rela- cionadas con el profesor y los estudiantes" (Grossman, Wilson e Shulman 2005: 7).}

Para Shulman (2000), ensinar envolve dois processos. Primeiro, saber o que os alunos pensam sobre o assunto. Em seguida, trabalhar com suas ideias: problematizar, reconstruir, refazer, corrigir, ampliar, o que, em suas palavras " $[. .$.$] is very hard$ work" (Shulman 2005: 133). Ele sugere os seguintes passos: planejar um tópico, envolvendo várias semanas de trabalho e incluindo os conteúdos exigidos, bem como uma saída a campo e a finalização com propostas concretas de agência social, cívica ou política (Shulman 1997). Existem seis princípios que orientam este tipo de aprendizagem coletiva.

The six principles which appear to characterize the conditions for authentic and enduring learning in the community of learners model are generative content; active learning; reflective thinking and practice; collaboration; passion; and community or culture [ênfase no original] (Shulman 1997: 17).

Tal forma de aprendizagem exige outro tipo de ensino. Por isso, é preciso formar professores para se aventurar na incerteza e trabalhar em equipe. Ele sugere o estudo de casos, em que os professores, também organizados em comunidades, discutam suas próprias práticas (ou as práticas de professores mais experientes), para que sejam capazes de transformar os conhecimentos a fim de privilegiar as aprendizagens dos estudantes.

Além disso, Shulman alerta que é preciso que as instituições (escolas e gestoras) sintam-se implicadas nestes processos, senão, será o mesmo que pedir um trabalho de Sísifo aos docentes (Shulman 1994: 4). Ele defende que é possível aprender com a experiência (Shulman 2002), mas é preciso cuidar com as implicações éticas de expor os jovens à prática de um novato. As opções curriculares devem girar em torno de ensinar sem ter necessariamente certeza de aonde os alunos vão levar. É preciso 
valorizar as dificuldades e belezas da surpresa dentro da rotina escolar.

Aprender com a experiência significa produzir novos artefatos a partir dela (textos, diapositivos, diários, entrevistas...) que ajudarão em sua própria reflexão e também como casos a serem estudados por outros. As proposições de Shulman se mostram interessantes para o tema proposto neste artigo. Mas é preciso questionar a aproximação entre o saber de referência às competências de ensinar não podem ser debatidas a partir da própria didática da História.

\section{E a didática da História?}

A expressão "Didática da História" (DH) é controversa. Nos anos de 1980, Piet Fontaine realizou uma enquete em busca de detectar compreensões existentes sobre o termo no mundo acadêmico de seu círculo. Ele conseguiu 21 respostas cujas diferenças e semelhanças suscitaram os seguintes problemas: 1) as más compreensões do termo não se referem apenas ao termo didática (que possui tom pejorativo nos Estados Unidos da América e no Brasil), mas, também, ao termo história; 2) não há consenso de que a didática da história seja um campo de pesquisa; 3 ) há quem restrinja o objeto da DH apenas ao ensino, há quem o vincule inextricavelmente à teoria da história, há quem a confunda com a didática geral, há quem a vincule com a consciência histórica e, finalmente, quem a conecte com a comunicação entre as pessoas comuns e o passado; 4) poucos tratam da escola conjuntamente com outros lugares educativos; 5) nem todos reconhecem as dimensões diversas que a DH pode abarcar (o que, como e por quê se ensina/aprende história); 6) por fim, uma semelhança importante: quase todos os participantes da enquete enfatizam a importância da $\mathrm{DH}$ em relação a projetos de futuro.

Fontaine demonstra seu ponto de vista: a $\mathrm{DH}$ se refere à pesquisa e ao conhecimento de tipo humanista, que tem por objetivo verificar como as pessoas de hoje usam o passado para resolver seus problemas. "History Didactics is the discipline of the communication between history and people" (Fontaine 1985: 2). O viés prático da DH se preocupa com a escola e com a formação de professores, mas também com todas as outras formas de expressão da cultura histórica na sociedade. Ainda segundo Fontaine, "History Didactics is an indispensable part of a current science of history and a necessary subject of a modern education of teachers of history for whom the conventional teacher training is not sufficient" (Fontaine 1985: 3).

A DH, portanto, seria indispensável para a formação de professores de história, pois ela estuda como se pensa historicamente, a partir de duas grandes linhas de reflexão: para que serve a história e como fazer melhor uso dela. Para Nicole Lautier e Nicole Ailleu-Mary (2008), a DH na França nasce diretamente conectada com as demandas escolares e segue ligada a estes problemas, sob a influência de Henri Moniot (um dos entrevistados por Fontaine). Entretanto, as autoras reconhecem a relevância de outros tipos de manifestação histórica como objeto de interesse da DH, mesmo que ainda bastante submetido ao mundo escolar.

Il n'y a pas seulement à transmettre des énoncés raisonnablement construits par les historiens, mais à assurer du même pas un rapport raisonnable avec les énoncés historiques, la pratique consciente des modes de pensée de l'histoire et la gestion raisonée des usages publics (Lautier e Ailleu-Mary 2008: 96).

Essas diferentes tradições sobre DH alimentam as compreensões brasileiras, como sintetizou Oldimar Cardoso (2008). No Brasil, o termo é utilizado em trabalhos que desejam argumentar contra a separação entre a historiografia e o ensino de história, principalmente para firmar este último como campo de pesquisa e não somente de intervenção prática. O artigo de Klaus Bergman "A história na reflexão didática" (1989/1990) pode ser considerado um marco inaugural nestas reflexões.

Bergman explica que a DH é a construção de pesquisas sobre o que é aprendido (empiria), o que pode ser aprendido (reflexão) e o que deveria ser aprendido (normatização) em História. No modo empírico, estuda-se a elaboração e a recepção de conhecimentos históricos, em seus mais diversos espaços. No modo reflexivo, a DH deve pensar sobre si mesma e, no modo normativo, deve analisar propostas, posicionar-se sobre elas e formular sugestões. Trata-se de pesquisa que não se limita à escola, mas que a entende como um dos espaços privilegiados de produção e de divulgação de conhecimento histórico.

Esta compreensão advoga pela ausência de separação entre a ciência da história e seus muitos 
processos de ensino e aprendizagem, na contramão do que tradicionalmente existe nos cursos de licenciatura em História no Brasil, como demonstrado no início deste artigo. Em síntese, para Bergman, a DH "[...] analisa e explicita os fatores didáticos imanentes da própria Ciência Histórica e investiga o significado geral desta para a vida cultural e espiritual e para a práxis social de seu tempo" (Bergman 1989/1990: 31) e, assim, construiria ligações entre a ciência histórica, a pedagogia, a psicologia e as ciências sociais ${ }^{3}$. Afinal, o ensino de história não acontece apenas com base nas metodologias de ensino, mas nas necessidades, objetivos e funções da história para os jovens e para a sociedade.

Nesse sentido, pode-se questionar se o estudo da didática da história, dentro das compreensões aqui apresentadas, substituiria a proposta de Pedagogical Content Knowledge, de Shulman? Seriam propostas com o mesmo sentido? É possível pensar na DH como solução para a distância entre teoria e prática na formação inicial de professores de história?

Talvez a interpretação oferecida por Luis Fernando Cerri ofereça algumas pistas para essas indagações. Para Cerri, DH é uma teoria da aprendizagem histórica, esta pensada a partir dos processos de consciência histórica conforme Jörn Rüsen, filtrados por uma concepção dialética sobre conscientização (Cerri 2010). O autor defende a aproximação, ou melhor, a unificação da formação de bacharéis e de licenciados, pois ciência e docência não são antípodas. A base, obviamente, é a concepção de DH como autorreflexão da História, permitindo afirmar que "[...] a produção do conhecimento tem uma dimensão educacional intrínseca" (Cerri 2008: 357).

As propostas baseadas na DH aproximam-se das preocupações do PCK: impedir o artificial distanciamento que se cria entre o saber, o ensino e a garantia de que outros aprendam. Entretanto, os textos sobre DH, principalmente no Brasil, raramente oferecem sugestões concretas sobre o trabalho do formador de professores, pelo menos na mesma forma que Shulman. Há, portanto, o desafio de construir, desenvolver e analisar, a partir dos referenciais da $\mathrm{DH}$, propostas para formação de professores de história de forma consequente ao referencial transformador adotado, tendo como objetivo a construção de conhecimentos históricodidáticos durante a formação inicial.

Assim, para finalizar estas reflexões, ponderam-se as contribuições teóricas com os resultados obtidos pela investigação empírica, levando em consideração a perspectiva da DH de que produzir conhecimento histórico, ensiná-lo e aprendê-lo possuem as mesmas raízes epistemológicas, mas que ter consciência disso não é suficiente para tornar-se um bom professor de história. Tal articulação seria de responsabilidade do formador de professores?

\section{Implicações para a pesquisa}

O projeto de pesquisa cujos resultados parciais são aqui utilizados iniciou-se em 2014 como parte das atribuições da autora como professora de uma instituição federal de ensino superior no Brasil. O projeto foi concluído em dezembro de 2016 e contou com dois bolsistas de Iniciação Científica. Os objetivos do projeto foram: analisar a formação continuada de professores de história a partir da produção conjunta de conhecimentos didáticos no interior do Programa Institucional de Bolsa de Iniciação à Docência - subprojeto História (PibidHistória $)^{4}$ e refletir sobre as formas de ensinar a ensinar história consequentes com o referencial de didática da história adotado.

A intenção não foi realizar uma avaliação do Pibid como política pública e, sim, analisar possibilidades de construção de conhecimento didático de forma coletiva, entre os professores supervisores e os bolsistas de iniciação à docência. A partir das interpretações de tais possibilidades, foram construídas reflexões sobre a atuação do formador de professores, compreendendo seus limites e potenciais perante os encontros entre professores de História com distintas experiências, proporcionados pelo Pibid.

Os relatórios de pesquisa foram devidamente analisados, corrigidos e aprovados pelos participantes. Estes são considerados produtores de dados e atuantes na correção ética dos resultados da pesquisa e na orientação das conclusões.

A pesquisa corroborou que a participação de professores experientes na formação inicial é essencial porque eles são capazes de ensinar mais do que técnicas de ensino: demonstram que é possível ser valorizado e trabalhar como um intelectual transformador, além de fazer pesquisa ao lado da prática. Os professores menos experientes também contribuem com a produção de conhecimentos histórico-didáticos, mas, em seus depoimentos, consideram que a oportunidade de participar do 
projeto serve mais para sua formação contínua do que para contribuir para a formação de seus futuros colegas.

A partir da revisão do pensamento de vários outros autores, Marcelo e Vaillant (2005) concluem que professores que se envolvem em projetos de supervisão de estágio sentem-se mais conectados com a profissão e ajudam a desenvolver, nos outros, conhecimento didático do conteúdo. A reflexão a partir da prática precisa, entretanto, do cuidado com o que os autores chamam de disonáncia crítica: é importante o contato com a realidade escolar, mas com cuidado para não ficar apenas com uma ou duas práticas, pensando que elas resumem todas as possibilidades da profissão. É preciso que os formadores deem oportunidade de conhecer outras escolas, de acompanhar colegas e de realizar outras tarefas.

Assim, o professor supervisor é mais que ensinador, é também formador dos outros e de si próprio. Desta perspectiva, acredita-se que a responsabilidade do formador universitário está muito próxima da concretização da conexão entre os diversos tipos de conhecimento e as práticas possíveis. Por essas razões, a formação inicial e contínua deveria contar com diversidade de experiências e não apenas com a sala de aula universitária, o que significa que os professores que avaliam as experiências em estágios não podem se limitar aos professores universitários.

Considera-se, ao final, que é preciso ampliar as referências que os professores em formação possuem sobre os mais experientes, vivenciar as práticas nas escolas e repensar o papel de formador por parte do professor universitário. A pesquisa atingiu, portanto, seu objetivo primordial: lançar luzes sobre o aprender a ensinar história do ponto de vista do formador universitário. Fica evidente que seu papel é de aproximar diferentes espaços de formação e proporcionar experiências profundas e reflexivas sobre a docência. Não se pode esperar que o professor universitário seja o responsável pela aproximação entre teoria e prática de maneira direta, pois suas experiências só podem ser acessadas como memória e as vivências da sala de aula universitária possuem outros objetivos.

Assim, verifica-se que são as estruturas gerais da formação inicial e contínua que precisam ser renovadas, repensando, igualmente, a carreira do formador de professores ligado com as práticas de ensino, pois suas atribuições extrapolam as tradicionais formas de executar o tripé ensino-pesquisa-extensão. Sua presença constante em escolas ou outros espaços educativos é imprescindível e as disciplinas não podem ter sua carga horária restrita à sala de aula universitária. A vivência com o Pibid torna tudo isso bastante evidente.

\section{Agradecimientos}

A autora agradece aos avaliadores da revista e aos bolsistas de Iniciação Científica Amanda Rocha (CNPq/Ufrgs) e Felipe Lerias (BIC/Ufrgs), que fizeram a leitura crítica deste texto.

\section{Referências Citadas}

André, M.; Cruz, G.

2012 A produção de conhecimento na RBEP (1998-

2010). Revista Brasileira de Estudos Pedagógicos v. 93 n. 234: 443-462.

Bergman, K.

1989/1990 A história na reflexão didática. Revista Brasileira de História v. 9, n. 19: 29-42.

Cerri, L.F.

2010 Didática da História: uma leitura teórica sobre a história na prática. Revista de História Regional v. 15 n. 2: 264-278.

Cerri, L.F.

2008 Os historiadores precisam de formação pedagógica? Algumas reflexões a partir da Didática da História. En Trajetória e Processos de Ensinar e Aprender: Práticas e Didáticas. Editado por C. Traversini et al., pp. 342-358. Edipucrs, Porto Alegre.
Conselho Nacional de Educação

2015 Resolução n. 01 de 2015. Disponível em: http://portal. mec.gov.br/conselho-nacional-de-educacao/atos-normativos-sumulas-pareceres-e-resolucoes?id=21028 Acesso em: 11 jan. 2016.

Costa, M.A.; Ferreira, C.A.

2015 Ensino, História e Educação com/sem Convergências. História \& Ensino v. 21 n. 2: 13-30.

Fernandes, A.; Sousa, J.J.

2014 Didática da história: mediadora entre teoria e ensino de história? História e Diversidade v. 4 n. 1: 39-53.

Fontaine, P.

1986 What is history didactics? Information: International Society for History Didactics v. 7 n. 2: 90-102.

Giroux, H.

1997 Professores como intelectuais transformadores. Os professores como intelectuais: rumo a uma pedagogia crítica 
da aprendizagem. Traduzido por Daniel Bueno. Editado por H. Giroux, pp. 157-164. Artes Médicas, Porto Alegre.

Grossman, P.; Wilson, S.; Shulman, L.

2005 Profesores de sustancia: el conocimiento de la material para la enseñanza. Profesorado. Revista de currículum y formación del profesorado v. 9 n. 2: 1-25.

Guimarães, S.

2001 A formação do professor de história no Brasil: novas diretrizes, velhos problemas. REUNIÃO ANUAL DA ANPED, Anais, pp. 1-14. Anped, Caxambu.

Lautier, N.; Ailleu-Mary, N.

2008 La didactique de l'historie. Revue française de pédagogie 162: 95-131.

Libâneo, J.c.

2012 O campo teórico-investigativo e profissional da didática e a formação de professores. Didática e formação de professores: perspectivas e inovações. Editado por M. Suanno e N. Rajadell, pp. 37-58. Ceped/PUC Goiás, Goiânia.

Marcelo, C.

1993 Cómo conocen los profesores la materia que enseñan. Algunas contribuciones de la investigación sobre Conocimiento Didáctico del Contenido. Las didácticas específicas en la formación del profesorado. Editado por L. Montero e J. M. Vez, pp. 151-186. Tórculo, Santiago de Compostela.

Marcelo, C.

2001 Aprender a enseñar para la sociedad del conocimiento. Revista Complutense de Educación v. 12 n. 2: 531-593.

Monteiro, A.M.F.C.

2003 A história ensinada: algumas configurações do saber escolar. História \& Ensino v. 9: 37-62.

Monteiro, A.M.F.C.

2001 Professores: entre saberes e práticas. Educação \& Sociedade 74: 121-142.

Pacievitch, C.; Cerri, L. F.

2010 Guerrilheiros ou sacerdotes? Professores de História, consciência histórica e construção de identidades. PróPosições, v. 21, pp. 163-183.
Pacievitch, C.

2014 Responsabilidade docente: utopias de professores de história. Curitiba: Appris.

Portelli, A.

1997 Tentando aprender um pouquinho, algumas reflexões sobre ética na história oral. Projeto História 15: 13-49.

Shulman, L.

1997 Comunities of learners and comunities of teachers. Mandel Leadership Institute, Jerusalém.

Shulman, L.

2014 Conhecimento e ensino: fundamentos para a nova reforma. Cadernos Cenpec v. 4 n. 2: 196-229.

Shulman, L.

2002 Forgive and remember: the challenges and opportunities of learning from experience. Launching the next generation of new teachers. Editado por B. Chase et al., pp. 58-66. Santa Cruz, University of California.

Shulman, L.

1994 Scholarship is a great story; reform is a long haul. The national teaching and learning forum v. 4 n. 1: 1-14.

Shulman, L.

2000 Teacher development: roles of domain expertise and pedagogical knowledge. Journal of the Applied Development Psychology v. 21 n. 1: 129-135.

Shulman, L.

2005 The Signature Pedagogies of the Professions of Law, Medicine, Engineering, and the Clergy: Potential Lessons for the Education of Teachers. Ponencia presentada en MATH SCIENCE PARTNERSHIPS (MSP) WORKSHOP: "Teacher Education for Effective Teaching and Learning", National Research Council's Center for Education Irvine, California.

Vaillant, D.; Marcelo García, C.

2001 Las tareas del formador. Aljibe, Málaga.

Valdés Puentes, R.; Longarezzi, A.

2015 Estado da arte sobre didática no Sudeste brasileiro: um estudo das pesquisas e produções desenvolvidas nesse campo. Comunicações v. 22 n. 3: 165-181.

\section{Notas}

1 A obra citada é Shulman, L. (1992). Renewing the Pedagogy of Teacher Education: The Impact of SubjectSpecific Conceptions of Teaching. Ponencia presentada al Simposium sobre Didácticas Específicas en la Formación de Profesores, p. 12.

2 Feiman-Nemser, S. y Buchmann, M. (1985). Pitfalls of experience in teacher preparation. Teacher College Record, 87 (1), 53-65.

3 Astrogildo Fernandes e José Josberto de Sousa também oferecem uma explicação semelhante:
"[...] DH, como campo disciplinar que se dedica ao aprendizado histórico, diverso de apreensões que tratam a didática como ciência da transmissão do conhecimento histórico [...]. A DH mantém interface epistemológica com a própria Teoria da História, o que confere a sua especificidade, ancorada na investigação da relação entre o ensinar e o aprender história" (Fernandes e Sousa 2014: 40).

4 Na nomenclatura do Pibid, bolsistas supervisores são os professores da escola básica que acolhem os licenciados e orientam suas tarefas. Os bolsistas de iniciação à docência (BID) são estudantes da licenciatura que atuam na escola. 